\title{
Study Regarding the Types of Incidence of Lower Limb Injuries in Romanian Badminton Players
}

\author{
Milon Alexandra Gabriela ${ }^{1 *}$ \\ ${ }^{1}$ University „Vasile Alecsandri” of Bacău, Calea Mărășești 157, 600115, Romania
}

Keywords: badminton, injuries, lower limbs

\begin{abstract}
Badminton is a very complex sport that requires the players to have speed, strength, endurance, and dexterity during the game. It is one of the most demanding racquet sports. Because of the changes in direction and of the jumping, many badminton players suffer from injuries in their lower limbs. Most badminton players suffer from various leg and foot injuries, such as: sprains, strains, ligament tears, etc. The rate of injury in badminton is quite high, and it is important for the athletes to perform a good warm up and to use special equipment for this sport, in order to prevent such injuries.
\end{abstract}

\section{Introduction}

Badminton is a relatively new sport in Romania, but is very popular, especially among children, because it doesn't require a special type of equipment, and can be learned relatively fast. Beside the fact that it is a pleasant sport, it is also dynamic, with high energy consumption. Lately, there is an increasing number of amateurs who started practicing this sport for various reasons - to play a professional sport, to have fun, or to lose weight. During a match, the badminton players must perform multiple movements, such as: forward, backward or lateral lunges, forward, backward or lateral jumps, changes in direction, etc. Movement in the court is performed with combinations of side steps, forward steps, jumps, and running.

The breaks during a badminton game are short, and many times the players are overworked. A badminton match can last from 30 to 90 minutes, during this time the breaks being short, only at half game or at the end of one game. At half game the breaks last for 1 minute, while at the end of the game, for 2 minutes. When the match is very tight, with long balls, the referee can give, on demand, a short break, during which the players can drink water, or wipe themselves with a towel.

According to Golds (2002), “during a game, a badminton player will be required to demonstrate: agility, flexibility, power/strength, speed, footwork, reaction”.

\footnotetext{
*E-mail: milon.alexandra@yahoo.ro;
} 
During a badminton match, which lasts between 30 and 90 minutes, the distance run by a badminton player is very large, up to five-six kilometers (during longer matches), this showing that it is a very demanding sport, because a large distance is run in a relatively short time and with little breaks. Considering that the badminton players are subjected to many changes in direction, jumps and lunges, it is normal for them to suffer from various injuries in their lower limbs. Many times, these injuries can occur because of fatigue during a match or during competition. Lately, the badminton competitions are organized on a special playing surface called a "carpet", which is soft and not slippery. If during most competitions, the matches are played on this "carpet", the training sessions are conducted on normal courts, with wood or Taraflex floors, and these changes can cause injuries. Most badminton players suffer from various ankle and knee injuries. Most of the times, the injuries occurred to badminton players are ankle and knee strains and sprains. These injuries occur mostly during competitions, when the players are subjected to a physical and mental effort that is more intense than during practice. During competitions, the players' effort is more intense than during their training, and most of the times the warm up is not performed properly (Golds, 2016).

The goal of the warm up is not just to raise blood pressure and respiration, its main objective is to warm the muscles. Classical physiology stated that once the muscle temperature is raised, the athletic output can improve and increase. Van'T Hoff 's Law proves that the speed of chemical reactions in a given system increases with temperature, with every 10 degrees $C$ the speed of the body reactions is accelerated by 2.7 times. In the body, the temperature increase after the effort is only of 102 degrees $\mathrm{C}$, but it is enough to accelerate the speed of the biochemical reactions by $30-50 \%$. On the other hand, a well warmed muscle is more excitable, in other words it contracts and relaxes faster. Warm up greatly decreases the likelihood for the muscle fibers to tear, an often encountered injury in sports.

During competitions, the athletes must watch out also for their diet and rest, the hydration being also very important during practice or competitions. Liquids are essential during practice and during competitions, but they have to be consumed often and in small quantities. In the case of athletes, a $2 \%$ loss of the body water is enough to have negative effects on their physical performance. A 5\% loss of their body water usually leads to exhaustion, and a $7 \%-10 \%$ loss is much more serious, even fatal. Considering all these points, good hydration in athletes is extremely important because the need for water is greater, in comparison to the people who do not practice any sport (Fii sportiv, 2017).

According to Grice, (1996) in his book, Badminton-Steps to Success, he say that "without proper warm-up, the chance of injury is greater" and also he say that "after strenuous activity you should cool down by allowing your body to gradually return to a normal pace. Then repeat stretching exercises whilw you are still warm. This cooldown helps to get rid of lactic acid built up during vigorous exercise and helps to prevent muscle soreness". 
This paper refers to only the injuries of players participating in senior competitions, regardless whether the players are rightfully in this age category, or are younger.

\section{Material and methods}

The aim of this paper is to try to know the types of incidence of lower limb injuries in Romanian badminton players.

In this paper, the hypothese was that in badminton the ankle injuries is big esspecialy during the competition.

The research methods which I have used are: documentation, inquiry and statistical-mathematical.

According to Smîdu Lenuţa and Smîdu Dănuţ, sports injuries may occur from various reasons, such as: "inadequate equipment, excessive effort or overstressing, the training surface, improper diet, low mobility, ligamentous laxity, overlength of the limbs” (Smîdu \& Smîdu, 2011).

In these study, I discuss only with badminton player which are or was in national team of seniors.

\section{Results and Discussions}

Table 1. Lower limb injuries occurring in badminton players

\begin{tabular}{lll}
\hline No. & Name & Injury \\
\hline 1. & R. C. & $\begin{array}{l}\text { Right knee ligament strain } \\
\text { Ankle sprain }\end{array}$ \\
2. & C. D. & Ankle sprain \\
3. & N. D. & Ankle sprain \\
Right knee ACL tear \\
M. & C. G. & Ankiscus tear \\
& & Ankle sprain \\
5. & V. M. & Ankle sprain \\
6. & R. R. & Left knee ACL tear \\
7. & P. C. & Right ankle sprain \\
8. & M. A. & Right ankle sprain \\
& & Sprain \\
9. & C. F. & Right ankle sprain \\
10. & O. S. & Right ankle sprain \\
11. & O. A. & Right knee ACL tear \\
12. & N.M. & Right ankle sprain \\
13. & P. I. & Meniscus tear \\
14. & S.C. & Ligament tear \\
15. & L. M. & Sole muscle stiffening \\
& & Achilles tendon \\
16. & D. R. & Knee ligament strain \\
17. & G.I. & Achilles tendon \\
\hline
\end{tabular}


As one can see in the table above, there are many badminton players who suffer from lower limb injuries and is important to say, that from 30 badminton players who participate in national tournaments, 17 suffer at list one injury. Among these injuries the paper does not mention muscle strains in various areas or muscle contractures that have occurred in almost every player, or other injuries in other body segments; the paper mentions only the most serious injuries that need a longer rehabilitation time. Although it is not a contact sport, one can see that there are many athletes who suffer from various lower limb injuries.

Among these athletes, 10 of them had at least once their lower limb in a cast for at least 10 days. According to the type of rehabilitation of each athlete, some of them have recovered well; others have had more serious problems.

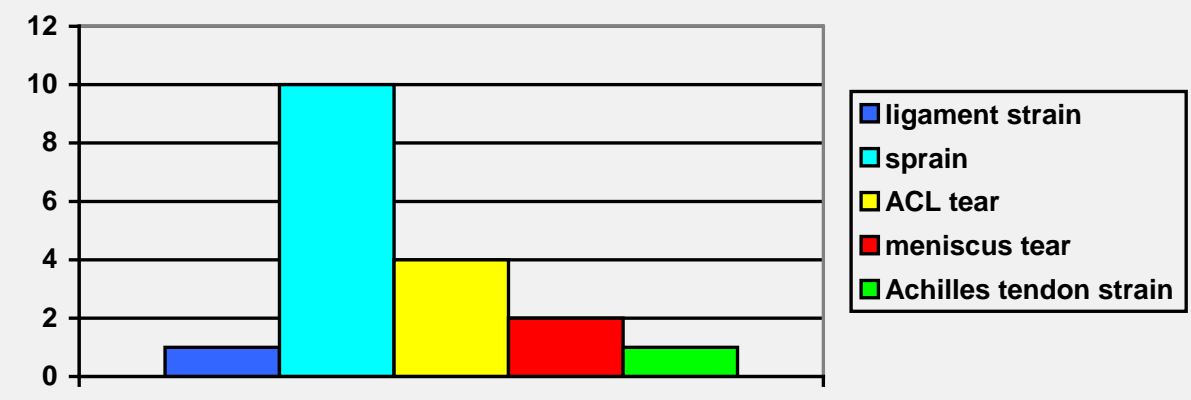

Figure 1. Reprezentation of most frecvent injuries

This figure 1 shows that most athletes suffer from ankle sprains. These sprains can be more or less serious, but most players have had their leg immobilized. Many of them have had their leg immobilized, but all of the players who have had injuries have participated in the national competitions after going through a rehabilitation program.

\section{Discussions}

Field specialists argue, that ankle sprain is a capsule ligamentar injury, which occurs foolowing some wrong movement. It most frequently happens after jumps or sudden changes of direction.

Even though the sprains are not that serious, the athletes need to have a resting period, during which they will apply ice on the injured ankle, and antiinflammatory or analgezic unguents for the pain. It is very important for the players to have a rehabilitation period after sitting with their legs in rest.

Some specialists in the field claim that injuries can occur from various reasons such as insufficient warm-up, improper work techniques, over use of joints, articular disorders, rapid weight gain, insufficient rest, poor diet, exhaustion or practice while in pain. (Bloss \& Hales, 1987).

Even if this paper addresses only the senior badminton players, this does not 
mean that only this age category has problems with their lower limbs; there are enough junior players who also have this kind of injuries.

In their book about badminton, Bloss and Hales (2000) say that especially when playing competitively, you should increase your body temperature for maximum performance.

\section{Conclusions}

Following the analysis of data I have found that the hypotesis according to which in badminton, the frequency of ankle injury during matches is high has been confirmed - from 17 athletes who suffered leg injuries, 12 had sprains.

It is very important for the athletes with sprains to have a recuperation period, and when they get back on the court, they must be careful not to make a great effort from the first training sessions and not to put too much pressure on the joint.

In most athletes these problems appear when they are not sufficiently trained physically, when their warm up was not sufficient, when their court movements are wrong or, why not, even when they are overworked and are lacking proper medication. Beside these injuries that can occur frequently enough in athletes, the badminton players can also suffer from spine and upper limb injuries. In order to prevent the lower limb and other type of injuries, it is well to remember several aspects, such as:

The athletes must warm up very well before practice and before every match;

- they must not overwork themselves, especially when they are tired;

- they must perform many drills to improve their joint mobility;

- an important role in preventing injuries is played by muscle strengthening;

I can say that our assumption was true, we can prevent legs injuries if we take care of same things.

There are many athletes who after a more serious injury want to return to competitions, but there are also athletes who need more time to regain their courage and confidence in themselves. For this reason, many athletes prefer to protect themselves by wearing ankle or knee braces, or even orthoses, because they feel safer this way.

\section{References}

1. BLOSS M.V., \& HALES R.S. (1987). Badminton, 1St Edition, USA: W.C. Brown;

2. BLOSS M.V., \& HALES R.S. (2000). Badminton, Eight Edition, USA: The McGraw-Hill Companies;

3. FII SPORTIV. (2017). Hidratarea şi necesarul de lichide, http://fiisportiv.ro/hidratarea-si-necesarul-de-lichide;

4. GRICE, T. (1996). Badminton - Steps to Success, USA: Human Kinetics;

5. GOLDS, M. (2002). Badminton - Skills of the game, eBook, UK: The Crowood Press; 
6. GOLDS, M. (2016). High Performance Badminton, eBook, UK: The Crowood Press;

7. NUTRITIE SPORTIVA. (2017). Principalele cauze ce duc la accidentare http://www.nutritiesportiva.ro/medicina_sportiva/18-principalele_cauze.html;

8. SMÎDU, N., SMÎDU, D. (2011, february). Importanţa cunoşterii factorilor de risc în traumatologia sportivă, Marathon, 3 , (http://www.marathon.ase.ro/pdf/vol3/1/NelutaSmidu.pdf).

\title{
Studiu Privind Incidența Tipurilor de Accidentări la Nivelul Membrelor Inferioare la J ucătorii de Badminton din România
}

\author{
Milon Alexandra Gabriela ${ }^{1}$ \\ 'Universitatea „Vasile Alecsandri” din Bacău, Calea Mărășești 157, 600115, România
}

\section{Cuvinte cheie: badminton, accidentări, membre inferioare}

\begin{abstract}
Badmintonul este un sport cu o complexitate mare, în care jucătorii în timpul meciurilor trebuie să dea dovadă de viteză, forţă, rezistenţă, îndemânare. Este de altfel unul dintre cele mai solicitante sporturi cu racheta. Din cauza schimbărilor de direcţie, a sărituriturilor foarte mulţi badmintonişti suferă accidentări la nivelul membrelor inferioare. Pentru a putea preveni accidentările sportivii trebuie să folosescă pantofi de sport speciali cu talpa foarte flexibilă, uşori şi cu pernă cu aer sau gel în călcâi şi să aibe grijă să se încălzească foarte bine înainte de antrenament sau meci. Rata accidenărilor este destul de mare în badminton şi este important ca sportivii să realizeze o buna pregătire a organismului pentru efort şi să folosească echipament special pentru acest sport pentru a preveni aceste accidentări.
\end{abstract}

\section{Introducere}

Badmintonul este un sport relativ nou la noi în ţară, dar care are priză foarte mare în rândul oamenilor şi mai ales al copiilor, deoarece nu necesită un echipament deosebit şi poate fi învăţat destul de repede. Pe lângă faptul că este plăcut, este un sport dinamic, cu consum mare de energie. În ultimul timp sunt din ce în cemai mulţi amatory care încep să practice acest sport din diferite motive: pentru a face un sport de performanță, pentru a se distra sau pentru a slăbi. În timpul jocului de badminton, sportivii trebuie să realizeze pe durata unei mingi mai multe mişcări, cum ar fi: fandări spre înainte, spre înapoi sau laterale, sărituri spre înainte, spre înapoi sau spre lateral, schimbări de direcţie, etc.

Deplasarea în teren se face cu ajutorul unor combinaţii între paşi adăugaţi, paşi laterali, sărituri şi alergare. Pauzele din timpul unui set de badminton sunt scurte, de multe ori sportivii fiind uneori foarte solicitaţi. Un meci de badminton poate dura de la 30 de minute la o oră şi 30 de minute, în tot acest timp pauzele 
sunt scurte, doar la jumătatea seturilor sau la finalul acestora. La jumătatea setului pauzele sunt de 1 minut, iar la sfârşitul setului pauzele sunt de 2 minute. În cazul în care este un meci foarte strâns, cu mingi lungi arbitrul mai poate acorda la cerere o pauză scurtă, în care sportivii pot bea o gură de apă sau să se şteargă cu prosopul.

În timpul unui meci de badminton, care durează între 30 şi 90 de minute distanţa parcursă de un jucător de badminton este foarte mare, aceasta putând ajunge şi până la cinci - şase kilometri (în meciurile de durată mai mare), asta înseamnă că este un sport foarte solicitant, deorece se parcurge o distanţă mare întrun timp relativ scurt şi cu pauze puţine.

După Golds, (2002),,În timpul unui meci, un jucător de badminton trebuie să demonstreze că are: agilitate, flexibilitate, putere/forţă, viteză, joc de picioare şi reacţie".

Având în vedere că jucătorii de badminton sunt supuşi la multe schimbări de direcţie, sărituri şi fandări, este normal ca aceştia să sufere diverse accidentări la nivelul membrelor inferioare. De multe ori aceste accidentări pot apărea şi din cauza oboselii apărute în timpul unui meci, sau în timpul competiţiei. În ultimul timp competiţiile de badminton se organizează pe o suprafaţă specială de joc, numită "covor", care este moale şi pe care nu se alunecă. Dacă la majoritatea competiţiilor se joacă pe acest "covor", antrenamentele se desfăşoară în săli normale, pe parchet sau teraflex, şi datorită acestor schimbări pot apărea aceste accidentări. Majoritatea badmintoniştilor suferă de diferite accidentări la nivelul gleznelor şi a genunchilor. De cele mai multe ori afecţiunile care apar la badmintonişti sunt entorsele, luxaţiile la nivelul gleznei, dar şi la nivelul genunchilor. Aceste accidentări apar de cele mai multe ori în competiţii, unde jucătorii sunt supuşi la un efort fizic şi psihic mai mare decât în timpul antrenamentelor. În timpul competiţiilor, efortul pe care îl depun jucătorii este mai mare decât efortul pe care aceştia îl depun la antrenament şi de multe ori nici pregătirea organismului pentru efort nu este realizată corespunzător (Golds, 2016).

Pregătirea organismului pentru efort nu are drept scop numai creşterea circulaţiei şi respiraţiei, principalul obiectiv este încălzirea masei musculare. Fiziologia clasică afirma că odată cu ridicarea temperaturii muşchiului se poate îmbunătăţi şi creşterea randamentului sportiv. Legea lui Van'T Hoff demonstrează că viteza reacţiilor chimice dintr-un sistem oarecare creşte odată cu creşterea temperaturii, cu fiecare 10 grade $\mathrm{C}$, viteza reacţiilor din organism se accelerează de 2,7 ori. În organism creşterea temperaturii în urma efortului este de numai 102 grade $C$, însă este suficient să accelereze cu $30-50 \%$ viteza reacţiilor biochimice. Pe de altă parte un muşchi bine încălzit este mai excitabil, cu alte cuvinte se contractă şi se relaxează mai repede. În acest timp prin încălzire scade în mare măsură posibilitatea de rupere a fibrelor musculare, accident des întâlnit în sport şi cunoscut sub denumirea de "clacaj".

În timpul competiţiilor sportivii trebuie să aibe grijă şi la alimentaţie şi la odihnă, iar hidratarea este şi ea foarte importantă în timpul antrenamentelor sau în timpul competiţiilor. Lichidele sunt esenţiale pe parcursul antrenementelor, dar şi al competiţiilor, doar că aceste lichide trebuie consumate des şi în cantităţi mici. În 
cazul sportivilor, este suficientă o pierdere de $2 \%$ din apa corporală, poate avea efecte negative asupra performanţei fizice. Scăderea apei corporale cu 5\% deobicei duce la epuizare, iar scăderea cu 7\% - 10\% este mult mai gravă, putând fi fatală. Din aceste puncte de vedere hidratarea corespunzatoare la sportivi este extrem de importantă deoarece necesitatea de apa este mai mare comparativ cu persoanele care nu practica un sport (Fii sportiv, 2017).

Grace, (1996) în cartea Badminton - Steps to success, afirma faptul că „fără o bună încălzire, şansele ca sportivii să se accidenteze cresc”, dar şi că "după efort, corpul trebuie să-şi revină treptat la normal, prin diferite exerciţii de stretching, de mers, astfel încât acidul lactic acumulat în timpul efortului să dispară şi să nu apară durerile musculare.”

În această lucrare vreau să mă refer doar la accidentările apărute la jucătorii care participă la competiţiile de seniori, chiar dacă aceştia sunt de drept la această categorie de vârstă sau sunt mai tineri.

\section{Material şi metode}

Scopul acestei lucrări este de a cunoaște incidența tipurilor de acccidentări la nivelul membrelor inferioare la jucătorii de badminton din România

În această lucrare am plecat de la ipoteza că în badminton incidența accidentărilor, la nivelul gleznei, mai ales în timpul concursurilor este mare.

Metodele de cercetare pe care le-am folosit sunt: metoda documentării, metoda anchetei, metoda statistico-matematică.

Smîdu Lenuţa, Smîdu Dănuţ, afirmau că ,accidentările la sportivi pot să apară din mai multe motive, cum ar fi: echipamentul inadecvat, suprasolicitarea sportivilor, suprafaţa de joc, alimentaţia incorectă, mobilitatea redusă, laxităţile ligamentare, lungimea exagerată a membrelor." (Smîdu \& Smîdu, 2011).

În acest studiu, subiecţii au fost 17 badmintonişti care participă în cadrul competiţiilor naţionale şi care fac, sau au făcut parte din lotul naţional de seniori.

\section{Rezultate şi discuţii}

După cum se observă în tabelul de mai sus, sunt mulţi badmintonişti care suferă accidentări la nivelul membrelor inferioare, mai ales având în vedere faptul că, dintr-un număr de 30 de sportivi care participă frecvent la competiţiile naţionale, 17 sportivi au suferit diferite accidentări. Printre aceste accidentări nu am amintit de întinderi musculare, în diferite zone sau contracturi musculare care au apărut aproape la fiecare jucător sau de alte accidentări apărute la alte segmente ale corpului, am abordat numai accidentările mai grave, care necesită timp mai lung de recuperare. Deşi nu este sport de contact, se poate observa că sunt mulţi sportivi care suferă de diferite accidentări la nivelul membrelor inferioare.

Dintre aceşti sportivi 10 dintre ei au avut măcar o dată membrul inferior în aparat ghipsat pentru cel puţin 10 zile. În funcţie de recuperarea pe care a facut-o fiecare sportiv în parte, unii s-au recuperat mai bine, alţii au avut alte probleme mai grave. 
Tabel 1. Afecţiuni care apar la nivelul membrelor inferioare la badmintonişti

\begin{tabular}{|c|c|c|}
\hline Nr. crt. & Nume, prenume & Accidentare \\
\hline 1 & R. C. & $\begin{array}{l}\text { Întindere de ligamente la genunchiul drept } \\
\text { Entorsă la nivelul gleznei }\end{array}$ \\
\hline 2 & C. D. & Entorsă la nivelul gleznei \\
\hline 3 & N. D. & Entorsă la nivelul gleznei \\
\hline 4 & C. G. & $\begin{array}{l}\text { Ruptură de ligamente încrucişate la } \\
\text { genunchiul drept } \\
\text { Fisură de menisc }\end{array}$ \\
\hline 5 & V.M. & Entorsă la nivelul gleznei \\
\hline 6 & R. R. & Entorsă la nivelul gleznei \\
\hline 7 & P. C. & Entorsă la nivelul gleznei \\
\hline 8 & M. A. & $\begin{array}{l}\text { Ruptură de ligamente încrucişate la } \\
\text { genunchiul stâng } \\
\text { Entorsă la glezna dreaptă }\end{array}$ \\
\hline 9 & C. F. & Entorsă la glezna dreaptă \\
\hline 10 & O. S. & Entorsă \\
\hline 11 & O. A. & Entorsă la glezna dreaptă \\
\hline 12 & N.M. & Entorsă la glezna dreaptă \\
\hline 13 & P. I. & $\begin{array}{l}\text { Ruptură de ligamente încrucişate la } \\
\text { genunchiul drept }\end{array}$ \\
\hline 14 & S.C. & Entorsă la glezna dreaptă \\
\hline 15 & L. M. & $\begin{array}{l}\text { Fisură de menisc } \\
\text { Ruptură de ligamente } \\
\text { Pietrifierea muşchiului din talpă }\end{array}$ \\
\hline 16 & D. R. & Tendonul lui Ahile \\
\hline 17 & G.I. & $\begin{array}{l}\text { Întindere ligamente genunchi } \\
\text { Tendonul lui Ahile }\end{array}$ \\
\hline
\end{tabular}
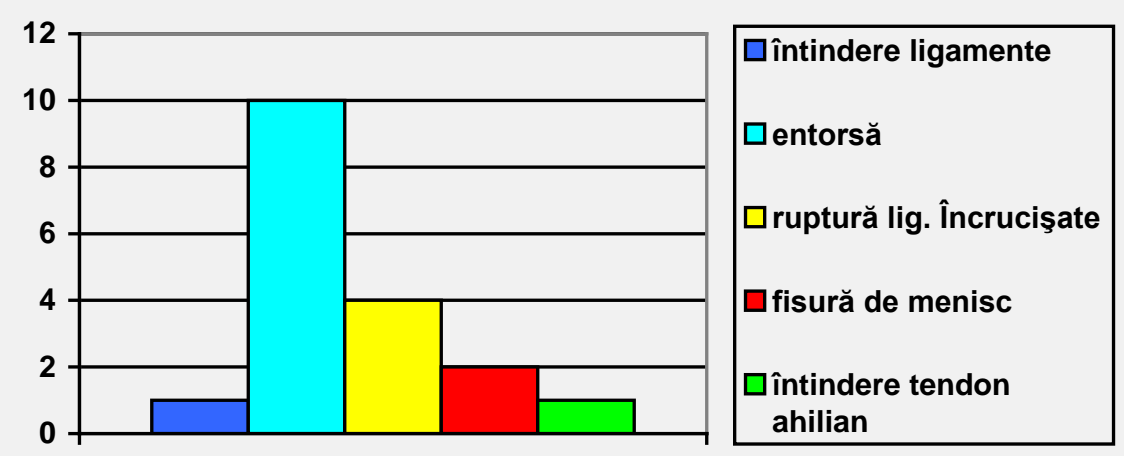

Figura 1. Reprezentarea celor mai frecvente accidentari

În figura nr. 1 se poate observa că marea majoritate a sportivilor suferă de entorse la nivelul gleznei. Aceste entorse pot fi mai grave sau mai uşoare, dar 
marea majoritate a sportivilor au stat cu piciorul imobilizat. Mulţi dintre aceşti sportivi au trebuit să stea cu piciorul imobilizat, dar toţi sportivii care s-au accidentat au participat iar în cadrul competiţiilor naţionale după ce au făcut o recuperare.

\section{Discuții}

Specialiştii în domeniu afirmă că entorsa reprezintă o leziune capsuloligamentară, care apare prin efectuarea unei mişcări anormale. Această accidentare apare cel mai des în urma unor sărituri sau schimbări bruşte de direcţie.

Deşi entorsele nu sunt atât de grave, este indicat ca sportivul să aibe o perioadă de repaus, timp în care va aplica pe glezna afectată gheaţă, creme antiinflamatoare sau analgezice pentru durere. Este foarte important ca sportivii să aibă o perioadă de recuperare după ce au stat cu piciorul în repaus.

Mai mulţi specialişti în domeniu susţin faptul că accidentările se pot produce din mai multe cauze, cum ar fi: încălzire insuficientă, tehnica de lucru incorectă, utilizarea în exces a unei articulaţii, dezechilibre articulare, creşterea rapidă a greutăţii, odihnă insuficientă, alimentaţie de proastă calitate, suprasolicitare sau chiar ignorarea durerilor acute (Bloss \& Hales, 1987).

Chiar dacă în lucrarea de faţă am zis că ne referim la badmintoniştii seniori, asta nu înseamnă că numai la această categorie de vârstă apar probleme la nivelul membrelor inferioare, sunt destui sportivi juniori care suferă de diferite acidentări la nivelul membrelor inferioare.

În cartea despre badminton, scrisă de Bloss and Hales (2000), aceştia spuneau că, mai ales în timpul competiţiilor, încălzirea organismului pentru efort trebuie realizată foarte bine pentru a îmbunătăţi performanţele.

\section{Concluzii}

În urma analizei datelor am constatat că ipoteza conform căreia în badminton incidența accidentărilor, la nivelul gleznei, în concurs este mare, s-a confirmat, având în vedere că din cei 17 sportivi care au suferit accidentări la nivelul membrelor inferioare, 12 dintre aceștia au avut entorse.

Pentru a preveni aceste accidentări la nivelul membrelor inferioare şi nu numai, este bine de ţinut cont de anumite lucruri, cum ar fi:

- sportivii trebuie să se încălzească foarte bine înainte de antrenament şi înainte de fiecare meci;

- trebuie să nu suprasolicite organismul, mai ales când sunt obosiţi;

- trebuie să facă multe exerciţii pentru îmbunătăţirea mobilităţii articulare;

- un rol important în prevenirea accidentărilor îl are tonifierea musculară.

Este foarte important pentru sportivii care au suferit de entorse, să aibe o perioadă de recuperare, iar în momentul în care revin pe teren trebuie să aibe grijă să nu facă un efort foarte mare de la primele antrenamente şi să nu încerce să forţeze articulaţia piciorului.

La majoritatea sportivilor aceste probleme apar atunci când nu sunt suficienţi de bine pregătiţi din punct de vedere fizic, când nu au realizat o pregătire suficientă 
a organismului pentru efort, din cauza faptului că deplasarea în teren este realizată greşit sau de ce nu, chiar din cauza unei suprasolicitări a organismului şi din lispa unei medicamentaţii adecvate. Pe lângă aceste accidentări care pot să apară destul de frecvent la sportivi, badmintoniştii mai suferă şi de alte afecţiuni la nivelul coloanei vertebrale, dar şi la nivelul membrelor superioare.

Pentru a preveni aceste accidentări la nivelul membrelor inferioare şi nu numai, este bine de ţinut cont de anumite lucruri, cum ar fi:

- sportivii trebuie să se încălzească foarte bine înainte de antrenament şi înainte de fiecare meci;

- trebuie să nu suprasolicite organismul, mai ales când sunt obosiţi;

- trebuie să facă multe exerciţii pentru îmbunătăţirea mobilităţii articulare;

- un rol important în prevenirea accidentărilor îl are tonifierea musculară;

- Putem spune că ipoteza de la care a plecat cercetarea este adevărată, şi chiar mai mult, această ipoteză s-a confirmat în urma discuţiilor purtate cu badmintoniştii care au suferit diverse accidentări, dar şi cu antrenorii.

Sunt mulţi sportivi care după o accidentare mai gravă doresc să revină cât mai repede în competiţii, dar pe de altă parte sunt sportivi care au nevoie de mai mult timp pentru a-şi recăpăta curajul şi încrederea în propriile forţe. Din acest motiv mulţi dintre sportivi preferă să se protejeze purtând glezniere, genunchiere sau chiar orteze, deoarece se simt mai în siguranţă. 